\title{
Design and Implementation of E-commerce Teaching Simulation Operating Platform
}

\author{
http://dx.doi.org/10.3991/ijoe.v10i1.2743 \\ Yongyong Zhu \\ Southwest University of Political Science and Law, Chongqing, china \\ Chongqing University of Education, Chongqing, China
}

\begin{abstract}
With the development of information technology, the traditional commercial trade activities are gradually substituted by the E-commerce, in order to better show the transaction process of among the manufacturers, shopping malls, logistics enterprises, foreign trade companies, banks and consumers to adapt to the development of E-commerce professional practice teaching, We designed the $E$ commerce teaching simulation operating platform, which is constituted by the E-commerce teaching simulation software, E-commerce simulation experiment management systems and E-commerce sand table. The platform can simulate the processes of E-commerce transactions, such as the electronic currency exchange, electronic trading market, electronic data interchange, supply chain management and enterprise financial management etc, through the combination of theory and practical operation to enable students to master the E-commerce practical skills from the emotional perspective and rational perspective to enhance students' understanding of E-commerce.
\end{abstract}

Index Terms-E-commerce, Teaching Simulation Operating Platform, CA Certification, Sand Table.

\section{INTRODUCTION}

E-commerce is a application way based on browser/ server, which is around the world a wide range of commercial trade activities and under the environment of Internet opening network, buyers and sellers do not need to see each other to carry out various business activities, thereby to bring about the consumer online shopping, online trading among merchants, online electronic payment, and a variety of business activities, trading activities, financial activities and related business operating model of comprehensive service activities [1]. E-commerce mainly includes the electronic currency exchange, supply chain management, electronic trading market, Internet marketing, online transaction processing, electronic data exchange, inventory management and automated data collection systems, etc., and mainly using the information technologies of Internet, extranet, email, databases, electronic IT directory and mobile phone etc. The characteristics of E-commerce decide the Ecommerce is a concept, rather than the simple use of electronic facilities to complete the business activities, it is a trading way of using advanced information technology, it is a collection of modern information technology and traditional business, through creating virtual market exchange places, perfect logistics system and security funds settlement system to complete the transaction [2]. The process of enterprises to carry out E-commerce involves large amounts of data need to be addressed, the manual entry alone is not only a waste of human and financial resources, and is more difficult to guarantee the convenient time and accurate statistics. In order to adapt to the development of E-commerce professional teaching, Ecommerce teaching simulation platform is emerged.

\section{THE DESIGN IDEAS OF E-COMMERCE TEACHING SiMULATION OPERATING PlATFORM OF MANUSCRIPT}

\section{A. The Design Philosophy of Software}

E-commerce teaching simulation operating platform is meet for the needs of E-commerce simulation training teaching, the development of E-commerce sites and Ecommerce observing teaching in the teaching process, through the establishment of the E-commerce teaching simulation operating platform to meet the unified management of all E-commerce experiment resources, improving the utilization rate of teaching resources [3]. Teachers can reasonably organize the E-commerce training arrangements to manage the whole process of students' experiments, and carrying out the unified management of students' experimental results, in addition to the teaching software, can also through the E-commerce three-dimensional sand table of sound, light, electricity etc to let the students understand the process of E-commerce transactions intuitively to enhance students' understanding of E-commerce.

\section{B. The Design Module of Software}

E-commerce teaching simulation operating platform module consists of three parts, including E-commerce teaching simulation software, E-commerce simulation experiment management system and E-commerce threedimensional sand table. E-commerce teaching simulation software is the presentation and demonstration of the whole development process of online store to guide students to complete the development of the online store project to equip students with the ability to quickly build E-commerce website and E-commerce sites' development to enable students to seize the advantage in the job competition [4]. E-commerce simulation experiment management system with enterprise management mode, which is using for the experimental process management of school students, mainly consists of four aspects of the organization of experimental resources, experimental plan arrangements, experimental process monitoring and experimental results' show, the system includes the internal and external E-commerce experiment and internship in the scope of management to facilitate the teaching managers control students' experimental situation at any time, which is conducive for late tracking and feedback effect. E-commerce three-dimensional sand table is using the highly simulation three-dimensional 
sand table teaching supplies to show the electronic processes of E-commerce, through sound, light and electricity to simulate the enterprise E-commerce operating processes in full range to help students to master the E-commerce business system, and through playing different roles of enterprises, banks, consumers, government departments, logistics companies etc, and with the different processes' demonstration of $\mathrm{B} 2 \mathrm{~B}, \mathrm{~B} 2 \mathrm{C}$, $\mathrm{C} 2 \mathrm{C}, \mathrm{B} 2 \mathrm{G}$ etc to let students fully recognize the variety of E-commerce processes, be familiar with and experience the interactive relationship among enterprises, banks, consumers, government departments and logistics companies, understand the business flow, logistics, capital flow and information flow of E-commerce operational modes. So that students not only examining the whole picture of E-commerce from a strategic perspective, but also from the perspective of implementation to firsthand experience the major aspects of E-commerce through Ecommerce teaching simulation operating platform, and through solving the typical problems encountered in practice to achieve the goal of learning by doing, learning to do something [5].

\section{The Content of Software Design}

E-commerce teaching simulation operating platform based on the Web browser / server structure that contains the E-commerce's business flow, information flow, capital flow, logistics, E-commerce domestic and international standards, laws and regulations, safety certification, credit and indispensable roles in business model: online stores, manufacturers, individual consumers, banks, online Trade and Industry Bureau, Electronic Malls, CA Center, logistics distribution [6]. E-commerce teaching simulation operating platform with the characteristics of rich content, large amount of information, simulation is convenient etc, students can individually or grouped to play the role of one or more to simulate $\mathrm{B} 2 \mathrm{~B}, \mathrm{~B} 2 \mathrm{C}, \mathrm{C} 2 \mathrm{C}, \mathrm{B} 2 \mathrm{G}$ and other trading environment, through the detailed commodity information and complete operational process to make students immersive.

\section{E-COMMERCE TEACHING Simulation SOFTware} DESIGN

\section{A. Software Functional Design}

E-commerce teaching simulation software provides real interactive teaching and practical environment, the system simulates network background involved in the process of E-commerce, providing business and trade sites, Online Shopping Malls, portals, search engines, email systems, government procurement, export online, online payment and other common network services platforms, and together with the teachers' back-office management functions and teaching tool, through the six roles of manufacturers, shopping malls, logistics enterprises, foreign trade companies, banks and consumers to demonstrate the efficacy and roles of the various aspects of E-commerce [7]. The software has training, teaching, experiment and practice several functions in one set to meet the needs of E-commerce practice teaching. The students in different roles within the purview of independent operation and use the services provided by network platform in the specific operation process, by establishing their own enterprises, creating corporate websites, corporate email application, digital certificate application/installation, EDI applications, the production of products, procurement, inventory, financial management, information dissemination, tender, export, customer management, event and task management, performance of the contract, financial services, online payments, transfers, billing, shipped goods, buyer receiving and other operations to complete the related processes and business of BTB, BTC CTC, BTC, online panic buying and other different types of transactions. The system is equipped with a small secretarial robot can give students kinds of reminders and helps, helping the students in timely to process all kinds of business to get more profit or meet more market demand for the role [8].

The software is suitable for educational training institutions to carry out E-commerce teaching and experiments, combining the E-commerce theory in textbooks with practice to make students to deepen awareness of the theoretical knowledge, master the practical application skills and E-commerce concept, strengthen perceptual knowledge and practical operational capacity [9]. Through the use of software, students can learn the detailed process of kinds of E-commerce trading patterns, and with the different roles to participate in it from different perspectives, independently conduct and use the E-commerce; and the management port is built-in the experiment, not only can well control experiments, but also by the appraisal management to realize the tracking and evaluation of the students' operation process and operation effects, which is convenient for the teachers to summarize and assess the experimental results.

\section{B. Software Functional Design}

In this system, we respectively simulate the main operational modes of E-commerce, such as the B2B and $\mathrm{B} 2 \mathrm{C}$, setting the online malls, production manufacturers, logistics companies, online banking, electronic mall and so on, considering from the system scalability, the software provides an open interface, online stores, manufacturers, and logistics companies, these types of business entities can be increased as needed. The system's development is constructed with high starting point, taking into account the forefront of the development of Ecommerce, so that students can quickly grasp the Ecommerce processes, improve teaching methods and quality.

The system setups these functions: providing administrators, teachers use, including user management, test management, process experimental management, basic information and other modules, which have functions of class management, experimental role management, enterprise management, product management, administrator management assessment management, and others.

Online banking functions: simulating banking system business management system, providing users with simulated online bank contains personal banking services, corporate banking services, electronic wallets bank card and other functions. This feature provides system the simulation of electronic payment, providing users with bank background management functions, such as account approvals, deposits, withdrawals, cancellation etc.

CA Certification Center: the digital certificate is issued by the authoritative and impartial third party that is the CA Center, the encryption technology with the core of digital certificates can carry out the encryption and 
decryption, digital signatures and signature verifications of the information of network transmission to ensure that the confidentiality and integrity, the authenticity of the identity of the trading entity and the non-repudiation of signature information of transmission's information to protect the security of network applications [10]. Through the CA Center module to enable students to understand the concept of CA certificates, providing the application, installation and using explanation of safety certificates, making the students have a better understanding of the Ecommerce security and related technologies [11].

Online industrial and commercial bureau: providing corporate registration, query, change, cancellation and other functions, it is the place that the administrators audit enterprises, popularize the industrial and commercial regulations.

The construction of sites: that is providing students to practice to establish a personal shop. Students establish the shop for the first time need to apply for a shop domain name first, choose their own preferred style to create the shop from the templates provided by the system, set up shop Logo and Banner, commodity classification; maintain the shop merchandise information, release online shop.

Electronic Malls: main functions of integrated email, membership management, membership registration, online store, trading platform, payment platform, logistics platform, digital certificate and search engine etc.

Network marketing: providing a variety of information release platforms, such as : releasing advertising, website links, and files on network marketing platforms, browse the news released by the administrator, participate in the online survey, use the search engines to find all kinds of information, through the way of the mailing list to subscribe E-magazine, participate in the discussion between BBS forum users and so on, using a variety of channels and methods to develop students' awareness of network marketing, and exercise the ability of students to participate in the network marketing activities [12].

Online Shopping Malls: Online Shopping Malls undertake the role of connecting in the process of merchandise sales; the task includes purchase products from suppliers or manufacturers, by the platform to show to the consumer, orders generated after the signing of the contract, processing orders with the network.

Logistics enterprises: the system simplifies the logistics into a single transport service provider, only a virtual role, which is primarily responsible for product transportation services, shipping the products of online store to the hands of individual consumers; shipping the products of manufacturers to the online store location, including coding management, account management, delivery and arrival management, task reminders, logistics knowledge and other functions [13].

Manufacturers:, manufacturing enterprises only play a role in providing products in the logistics supply chain, the function is similar with the shopping malls provide consumers with goods, just both of them adopt different ways in the sales. Therefore, we carry out the simplification on the basis of the mall, retaining only part of the inventory management, omitting manufacturing enterprises' procurement, thereby forming simple MIS system [14]. Through the system, reception can achieve a data query and search capabilities, background can process the $\mathrm{B} 2 \mathrm{~B}$ business dealings and logistics data query etc.

\section{The Design of E-COMMERCE Simulates EXPERIMENTAL MANAGEMENT SYSTEM}

\section{A. Software Functional Design}

E-commerce simulation experimental management system uses the management model of whole-process enterprises' practice, which is used for the whole-process management of students' E-commerce practical teaching; the laboratory management system includes the campus E-commerce professional management aspects into the computer management range, and by the software to carry out the whole-process management of students' experimental teaching [15]. E-commerce simulation experimental management software's processes including the aspects of the organization of experimental resources, arrangements of experimental plan, monitoring of experimental process and show of experimental results etc, teachers can control students' experimental operating situations by long-distance control to facilitate real-time tracking feedback teaching effectiveness, through the software platform can unified and effectively manage the experimental resources, achieving the effective use and accumulation of teaching resources.

E-commerce simulation experimental management system can allocate and replace the experimental resources, administrator can add the experimental courses opened by the E-commerce profession to the system, the text, Web links, Office documents, PDF files, video files, Flash, EXE executable files as well as a variety of generic courseware modes involved in experimental courses all can be added and edited through the system, and various experimental resources also can be published through the management system conveniently and efficiently [16]. Students can conduct the online experiment through their own account, though the experimental management system to simulate to punch the clock, edit individual work plans and training tips, organize panel discussions, write experimental work log according the request and so on, and uploading experimental results between the end of the experimental stage, the students carrying out the peer assessment of results etc. Through the management system, teachers can set experimental parameters, experimental procedures, experimental content, experimental evaluation methods, users as well as the roles of the division of authority etc to control the progress and results of students' experimental various stages at any time. The standardized experimental management systems take full advantage of the experimental resources to arrange the experimental classes, experimental time, experimental locations, experimental subjects and experimental curriculum to maximize the savings of teaching resources, enhance the effectiveness of teaching.

\section{B. The Functions of Software Modules}

The functions of E-commerce simulation experimental management system software module mainly consider the part of both teachers and students. The teachers act as system administrators, the main functions are the Ecommerce experimental resources management, information resources management, experimental tissue, experimental management and experimental evaluation [17]. Students act as experimental participant roles, 
mainly functions are personal information management, the management of experimental process, the management of experimental data, the functional module of $E$ commerce simulation experimental management system shown in Fig 1.

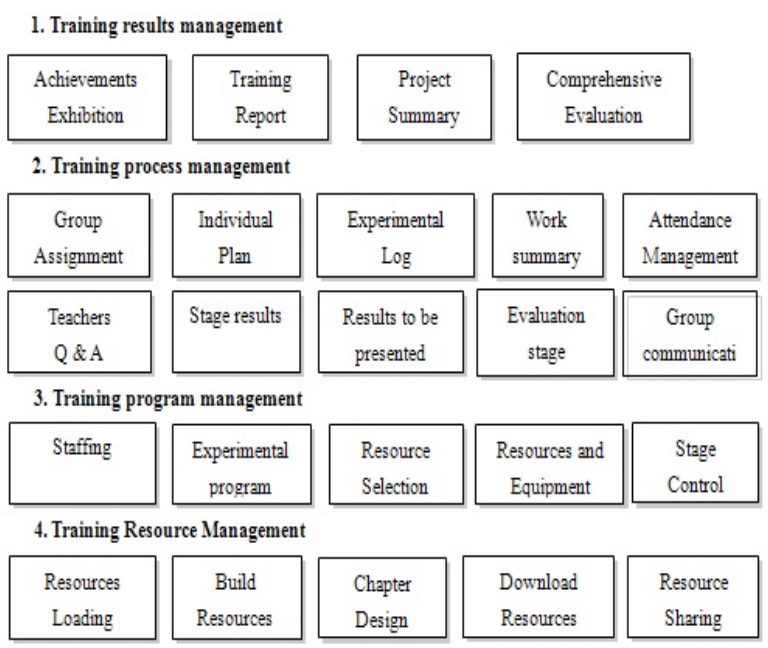

Figure 1. The functional module of E-commerce simulation experimental management system

Experimental resource management module: mainly includes basic information management, chapter content management, data download management and experimental stage design. The basic information is that the content of management experiments focus, difficulty, process and others. Chapter content management is through the ways of online editing, offline editing and centralized import to import office documents, video, supporting courseware, PDF documents and other attachments related with experiment to the simulation experimental management system to achieve centralized management. Data download management is managing the links information and download information, and can update the experimental resources at any time. The design of the experimental stage is that setting up chapters' content in various stages of the experiment, dividing the experimental content in accordance with the actual working shift.

Information resource management module: mainly includes experimental notice, experimental answering and information feedback. Experimental notice is the interactive information platform, teachers can send experiment information to the designated students through the experimental notification system, and students understand the experimental requirements by viewing the information. Experimental answering is that students ask teachers questions according to the problems encountered in the course of the experiment, through system feedback questions' answering processes and the issues central tendency, which is convenient for teachers to master the experimental progress of students to understand the students' mastery of experiments. Information feedback is analyzing and sorting out the data based on experimental question answering, and reflecting students' understanding of the experiment in the form of reports and charts.

Experimental organization module: mainly includes team management and experimental settings. Team management is that the students participate in the experiment group are divided in accordance with the experimental content, which is easy for teachers assign experimental task, evaluating the experimental results. Experimental settings are that setting the experimental process, arranging personnel, time, and location involved in the experiment as well as kinds of notification and task publishing.

The experimental management module: mainly including the experimental process management, log management, results management and other managements. Experimental process is that according to the experimental task to manage the entire experimental process, including experimental task issuing and recovery, examining the stage experimental results submitted by the students, auditing applications of students enter into the next phase of experiment, the stage evaluation of students' achievement and so on, Log management is managing the student's work log, which is easy to record the situation of students' experiment to understand students' learning progress. Results management is managing the experimental results in various experimental stage submitted by students that is convenient for teachers to master the progress of the experiment.

Experimental evaluation module: mainly includes the background evaluation, process evaluation, outcome evaluation and comprehensive evaluation. The background evaluation includes the experimental preparation evaluation, the evaluation of experimental designing reasonableness, team members' collaborative evaluation and other evaluation. The process evaluation is the unification of phase evaluation and the evaluation of the whole process, including the evaluation of the completed experimental situation in various stages, the solutions of finding problems and phenomena, the effect of solutions, the completion of the overall objectives and matching tasks etc. The results evaluation is the comprehensive evaluation of the practical operating results evaluation and the evaluation of students explore the unknown, find the experimental law. The comprehensive evaluation of experiment is the comprehensive result based on the background evaluation, process evaluation, the evaluation of result, it is the evaluation findings obtained from comparing and analyzing the advantages and disadvantages for the first three kinds of evaluation results.

Personal information management module: mainly includes the basic information of personal information with students' name, gender, profession, class, experimental courses and experimental content. Students can carry out the operations through the management of personal information, such as looking over the personal message, examining announcement, changing personal information and team information etc.

The experimental process management module: mainly includes experimental attendance management, experimental notification management, the checking of group task, experimental process control, and experimental results' submission, experimental phase application, a summary of the experimental stage and so on. Students can sign in and drop out, check the experimental internal notification, group task allocation, exchanges and discussions within the group, set their own work plan and experimental tasks, control the progress of the experiment, improve the experimental process, submit experimental results, submit the stage applicants of entering into the next stage, publish and manage the 
PAPER

DESign AND IMPLEMENTATION OF E-COMMERCE TEACHING SimUlation OPERATING Platform

experimental summary of personal stage and others through experimental process management [18].

Experimental data management module: mainly includes experimental data registration, distribution of experimental data, experimental data download and returning experimental data. Through the experimental data management module, students can record the registering, usage and returning of experimental consumables information, and also can download the experimental related electronic information and learning tutorials through the system, students can carry out selflearning except the teachers' teaching, students' independent learning system shown in Fig 2.

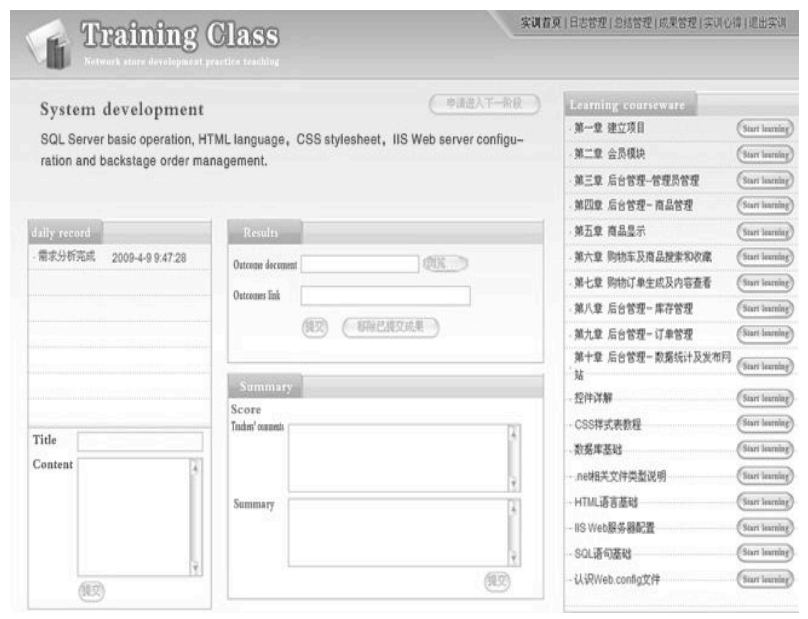

Figure 2. Students' independent learning system

\section{The Design of E-COMmerce SAnd TABle}

E-commerce sand table is the tool to simulate the Ecommerce enterprise operations process, E-commerce sand table is divided into $3 \mathrm{D}$ stereoscopic projection sand table, deducing sand table and multimedia sand table.

3D stereoscopic projection sand table is achieved through the polarization principle of light, using two projectors show images synchronously, making the polarization direction of the polarizer before the two projectors are perpendicular to each other, so that the polarization direction of the two polarized beams will be perpendicular to each other, the polarized light casts onto the projection screen then reflects to the audience position, the polarization direction does not change, the audience see polarized image through polarized glasses, thereby producing three-dimensional feeling in the visual nervous system. The presentation methods for watching threedimensional images have passive and active method, the passive method is that when watching requires special glasses, the glasses adopt image polarizer to distinguish between left and right eye information, the polarizer divides divergent rays into horizontal and vertical planes to finish the distinction of the eyes information. The active method requires glasses with a built-in LCD shutter to convert the left and right eye information, a separation of the IR transmitter to send synchronous information to the glasses.

The deducing sand table is through simulating the overall operating process of E-commerce enterprises to make students have following aspects' training, such as the orders and purchasing, payable and receivable, bills funding, customer relationship management, process management, production management, payroll management, stocking-selling-storing, custom reports, decision-making support, fixed assets, accounting general ledger and other aspects. Through the students participate in all aspects of E-commerce sand table to understand the process control of all aspects of enterprise E-commerce from a strategic height and implementation point of view, the students not only should carry out the strategic planning of a long period of time and more nodes enterprises' overall operation, but also consider the tactical formulation in various short-term operating period. The deducing sand table is by introducing a variety of enterprise operation and management tools, using quantitative and qualitative analysis method to enhance the students' system operating capacity, when the students participate in the deducing sand table experiments need to take full account of collaboration capability of team members, balancing the ratio of enterprises' all costs and income.

Multimedia E-commerce show sand table trains students' awareness of all aspects of E-commerce from the overall through reproduction and simulation of the real scene, and can show the visual image of E-commerce working environment as well as the interconnectedness of related units, which can help students to mark profoundly the actual scene in the mind with a way of across the panorama, multimedia E-commerce show sand table shown in Figure 4. Multimedia E-commerce show sand table has the advantages of realistic modeling, well visual effects, beautiful appearance, strong pressure resistance, rigid-flexible combination, damp and crack control and others, which can show in the full range of simulation dynamic, you can control it with the use of automatic or manual operation. Intuitive multimedia electronic display sand table fully simulate the actual operating conditions of enterprise, and using the most intuitive way to let the students experience and learn the complex, abstract operating management theory, experiencing the complete enterprise operating process in the training, and feeling the typical course of the development of enterprises. By training students on the proper positions awareness and collaboration awareness, understand the laws of scientific management, and learn to penetrate the enterprise operating management from a financial point of perspective to enhance business plan, business decisionmaking and implementation capacity, and lay the foundation for the formation of the students' ability to initiate and operate independently, multimedia Ecommerce show sand table in Fig 3.

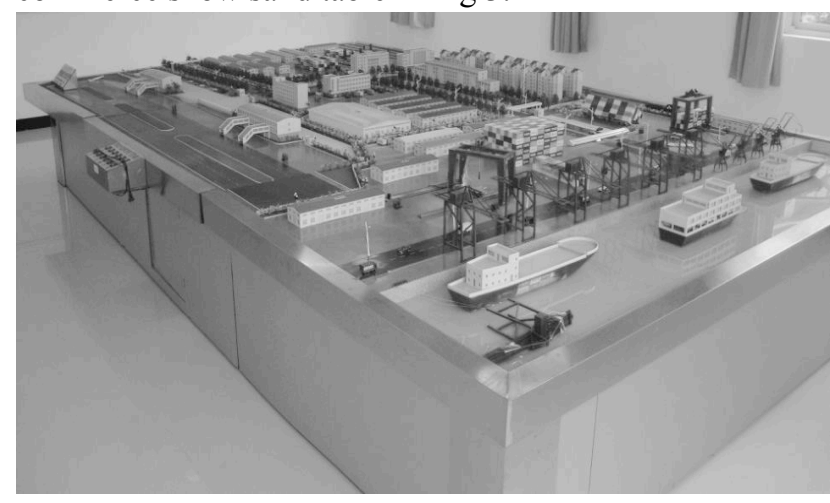

Figure 3. Multimedia E-Commerce show sand table 


\section{CONCLUSION}

E-commerce teaching simulation operating platform is made up with three parts of the E-commerce teaching simulation software, E-commerce simulation management system and E-commerce sand table. The platform with functions of training, teaching, experiment and practice as a whole set, through the combination of E-commerce theory and practical operation to enable students to deepen awareness of the theoretical knowledge, grasp the Ecommerce actual application skills and enhance perceptual knowledge and practical ability, which can be able to fit a variety of educational and training institutions to carry out E-commerce teaching and experiment to meet the needs of E-commerce practical teaching.

E-commerce teaching simulation operating platform enables students to participate in a variety of transaction types of BTB, BTC, CTC, BTC and online purchase from different perspectives with different roles, through the establishment of their own enterprises, creating corporate websites, email applications of enterprises, digital certificate request and installation, EDI application, the production of products, purchasing, inventory, financial management, information dissemination, the tender, import and export, customer management, event and task management, the performance of contract, financial services, online payment, transfer billing, delivery and receipt and other operations, the students can learn the detailed process of kinds of E-commerce trading patterns, autonomously carrying out the learning of E-commerce experimental curriculums, the software built-in assessment and evaluation modules are facilitating the teachers to track and evaluate students' operating process and operating effects that teachers can keep students' learning progress and effect of E-commerce experiments. The use of E-commerce teaching simulation operating platform enables students to autonomously conduct business interaction among the six roles of manufacturers, shopping malls, logistics enterprises, foreign trade companies, banks and consumers to fully experience the transaction process and the core concept of E-commerce.

\section{ACKNOWLEDGMENT}

This work is supported by the Humanity and Social Science Youth foundation of Ministry of Education (No. 13YJC880133), Chongqing Education Committee Educational Reform (No.1202096), Chongqing education science planning (No.2013-ZJ-065) and the Research Foundation of Chongqing University of Education (No.JG201210).

\section{REFERENCES}

[1] D. Gefen, "E-commerce: the role of familiarity and trust," Omega: Oxford Pergamon Press, vol. 28, no. 6, pp. 725-737, 2000.

[2] M. S. Shahibi and A. P. D. Z. AB, "Security Factor and Trust in ECommerce Transactions," Australian Journal of Basic and Applied Sciences, vol. 5, pp. 2028-2033, 2011.

[3] R. Bhatia, M. Dave, R. C. Joshi, "Retrieval System for Distributed Component Repositories," International Review on Computers and Software, vol. 2. no. 2, pp. 118-123, 2007.

[4] D. Boud, R. Cohen, and J. Sampson, "Peer learning and assessment," Assessment and Evaluation in Higher Educ., vol. 24, no. 4, pp. 413-426, 1999. http://dx.doi.org/10.1080/02602939 $\underline{90240405 .}$.
[5] S. Minocha, "A case study-based investigation of students' experiences with social software tools," New Review of Hypermedia and Multimedia, vol. 15, no. 3, pp. 245-265, 2009. http://dx.doi.org/10.1080/13614560903494320.

[6] D. Boud, and A. Lee, "Peer le arning as pedagogic discourse for research education," Studies in Higher Educ., vol. 30, no. 5, pp. 501 - 516, 2005. http://dx.doi.org/10.1080/03075070500249138.

[7] D. Boud, R. Cohen, and J. Sampson, "Peer learning and assessment," Assessment and Evaluation in Higher Educ., vol. 24, no. 4, pp. 413-426, 1999. http://dx.doi.org/10.1080/0260293990 240405

[8] R. El Bejjet, H. Medromi, "A Generic Platform for a Multi-Agent Systems Simulation," International Review on Computers and Software, vol. 5. no. 5, pp. 505-509, 2010.

[9] Li YR, Zhu YY, Zhang CN, "The K-Means Clustering Algorithm Based On Chaos Particle Swarm," Journal of Theoretical and Applied Information Technology, vol. 48. no. 2, pp. 762-767, 2013.

[10] Zhang CN, YY Zhu, YR Li. "An Improved Semi-supervised Clustering Algorithm Based on Active Learning," Journal of Theoretical and Applied Information Technology, vol. 48. no. 2, pp. 741-748, 2013.

[11] Zhu YY. "QuickTime Virtual Reality Technology Applies to Practical Teaching Recording System," TELKOMNIKA Indonesian Journal of Electrical Engineering, vol. 11. no. 11, pp. 6315-6320, 2013.

[12] S. A. Aghdaie, S. Fathi, A. Piraman, "An Analysis of Factors Affecting the Consumer's Attitude of Trust and their Impact on Internet Purchasing Behavior," International Journal of Business and Social Science, vol. 2, no. 23, pp. 147-158, 2011.

[13] Zhu YY. "Research on the Data and Transaction Security of Enterprise E-Commerce Countermeasure," International Journal of Security and Its Applications, vol. 7, no. 6, pp. 259-268, 2013. http://dx.doi.org/10.14257/ijsia.2013.7.6.27

[14] P. Drázdilová, G. Obadi, K. Slaninová, J. Martinovic and V. Snásel, "Analysis and visualization of relations in eLearning," in Computational Social Network Anal: Trends, Tools and Research Advances," A. Abraham, A-E. Hassanien and V. Snásel, Eds. London: Springer-Verlag London, 2010. http://dx.doi.org/10.1007/ 978-1-84882-229-0 11.

[15] Zhu YY. Research on Practical Teaching Recording System Based on QuickTime Virtual Reality Technology, International Journal of Online Engineering, vol. 9, no. 5, pp. 4-8, 2013. http://dx.doi.org/10.3991\%2Fijoe.v9i5.2606

[16] Zhu YY, “The design and solution of students' entrepreneurial practice ability training cloud platform," International Journal of Smart Home, vol. 7. no. 6, pp. 317-328, 2013. http://dx.doi.org/10.14257/ijsh.2013.7.6.31

[17] Zhu YY, "Research on the E-commerce practice teaching simulation operating platform", ICIC Express Letters Part B: Applications, vol. 5, no. 4, pp. 1033-1038.

[18] MA C, Zhu YY, "Analysis and Extraction of Fingerprint Features Based on Principal Curves", Journal of Computational Information Systems, vol.9, no.21, pp. 8591-8601, 2013.

\section{AUTHOR}

Yongyong ZHU received her B.S. degree in Computer Science from Southwest Agricultural University, and he M.S. degree in educational technology from Southwest University, in 2003 and 2009, respectively. He is currently working towards a Ph.D. at Southwest University of Political Science and Law. Since 2011 he has been working as Associate Professor at the Department of Economics and Business Administration of Chongqing University of Education, Chongqing, People's Republic of China (zhuyongyong@126.com).

Submitted, May, 8, 2013. Published as resubmitted by the authors on November, 1, 2013. 